\title{
In-Hospital Mortality and Complication Rates According to Health Insurance Data in Patients Undergoing Hyperthermic Intraperitoneal Chemotherapy for Peritoneal Surface Malignancies in Germany
}

\author{
Lisa Überrück, $\mathrm{MD}^{1,2}$, Giorgi Nadiradze, $\mathrm{MD}^{1,2}$, Can Yurttas, $\mathrm{MD}^{1,2}$, Alfred Königsrainer, $\mathrm{MD}, \mathrm{PhD}^{1,2}$, \\ Ingmar Königsrainer, $\mathrm{MD}, \mathbf{P h D}^{3}$, and Philipp Horvath, $\mathbf{M D}^{1,2}$ \\ ${ }^{1}$ Department of General, Visceral and Transplant Surgery, Comprehensive Cancer Center, University of Tübingen, \\ Tübingen, Germany; ${ }^{2}$ National Center for Pleura and Peritoneum, University of Tübingen, Tübingen, Germany; \\ ${ }^{3}$ Department of General, Visceral and Thoracic Surgery, Feldkirch Academic Teaching Hospital, Feldkirch, Austria
}

\begin{abstract}
Background. Morbidity and in-hospital mortality rates of patients undergoing cytoreductive surgery and hyperthermic intraperitoneal chemotherapy in Germany are not known.

Methods. From 2009 to 2018 all patients undergoing cytoreductive surgery and hyperthermic intraperitoneal chemotherapy in Germany were retrospectively analyzed regarding morbidity and in-hospital mortality rates according to nationwide hospital billing data based on diagnosis-related groups (DRG). The "failure to rescue" (FTR) index, characterizing patients who died after severe but potentially manageable complications, was calculated. Results. In total, 8463 patients were included and analyzed. Female sex predominated (1.5:1). Colonic origin of peritoneal metastasis was highest throughout all years, reaching its highest level in $2017(55 \% ; n=563)$ and its lowest level in 2012 (40\%; $n=349)$. Median length of hospital stay reached its maximum in 2017 at 23.9 days and its minimum in 2010 at 22.0 days. Analysis of the total FTR index showed a noticeable improvement over the years, reaching its lowest values in 2017 (9.8\%) and 2018 (8.8\%). The FTR index for sepsis, peritonitis, and pulmonary complications significantly improved over time. Of
\end{abstract}

(C) The Author(s) 2020

First Received: 20 May 2020

Accepted: 15 October 2020;

Published Online: 9 November 2020

P. Horvath, MD

e-mail: philipp.horvath@med.uni-tuebingen.de the 8463 included patients, 290 died during hospital stay, reflecting an in-hospital mortality rate of $3.4 \%$.

Conclusion. In-hospital mortality after cytoreductive surgery and hyperthermic intraperitoneal chemotherapy is reasonably low compared with other surgical procedures. The improvement in the FTR index reflects efforts to centralize treatment at specialized high-volume centers.

In the past, pre- or intra-operative diagnosis of peritoneal surface malignancies (PSM) prompted the interdisciplinary decision to abandon further surgical efforts, and patients underwent systemic chemotherapy with poor prognosis, mostly due to progression of peritoneal tumor implants resulting in intestinal obstruction and ultimately death. In the last couple of years, improvements in palliative chemotherapy and cytoreductive surgery (CRS) with hyperthermic intraperitoneal chemotherapy (HIPEC) were able to achieve a survival benefit for a selected subset of patients with colorectal, ovarian, appendix peritoneal metastasis, mesothelioma, and pseudomyxoma peritonei. ${ }^{1-17}$ After almost 20 years of HIPEC administration, the process of selecting appropriate patients underwent an outstanding evolution. Meanwhile, there are a variety of positive and negative prognostic factors (patient, tumor, and molecular pathological features) that influence the decision-making process to reduce postoperative morbidity and mortality rates and optimize the oncological benefit. A large number of publications have focused on the occurrence, severity, and predisposing parameters of CRS- and HIPEC-associated morbidity in recent and past literature. ${ }^{18-23}$ However, the major problem 
is the comparability of results, because indications, HIPEC protocols, surgical techniques, and documentation of adverse events are not uniform. A systematic review published in 2009 including 24 centers reported a major morbidity rate ranging from 12 to $52 \%$ and a mortality rate ranging from 0.9 to $5.8 \%{ }^{24}$ The majority of data come from countries other than Germany and often depict a selected subset of patients, thus making interpretation difficult. The true in-hospital mortality and complication rates after CRS and HIPEC in Germany are not known. Furthermore, the quality of interdisciplinary management of severe but potentially treatable complications, as assessed by the "failure to rescue" (FTR) index ${ }^{25}$ is not known.

To obtain a valid insight into the quality of care of patients following CRS and HIPEC for PSM in Germany, we conducted a nationwide analysis to obtain in-hospital mortality and complication rates. Furthermore, the FTR index, characterizing those patients who died due to a severe but potentially manageable complication, was calculated.

\section{PATIENTS AND METHODS}

Data on all patients treated from January 2009 to December 2018 were obtained from the nationwide German diagnosis-related group (DRG) statistics hosted by the German Federal Statistics Office. Data management strictly followed German data protection regulations. Patients with OPS (German procedure codes) code 8-546.0 (hyperthermic intraperitoneal chemotherapy) were included, and analysis was restricted to patients with complete data records. The OPS registry is a modified version of the International Classification of Procedures in Medicine (ICPM). The procedure had to be performed in a German hospital.

Data included primary diagnoses according to ICD-10 (ICD-10-GM) classification, sex, gender distribution, length of hospital stay, performed procedures according to the respective OPS codes, in-hospital mortality, and morbidity rates. The calculated FTR index describes the proportion of patients who died during hospital stay due to a severe but potentially treatable complication. The following severe complications were included according to their respective ICD-10-GM codes and analyzed: sepsis, myocardial infarction, acute pulmonary embolism, pneumonia, peritonitis, anastomotic insufficiency, and acute gastrointestinal bleeding.

Separate calculations of the FTR index were performed for pulmonary and bleeding complications. The FTR index (pulmonary) included the following diagnoses according to their respective ICD-10-GM codes: respiratory insufficiency, acute pulmonary embolism, pneumonia, pleural effusion, and ventilation $>24 \mathrm{~h}$. The FTR index (bleeding) included the following diagnoses according to their respective ICD-10-GM codes: acute bleeding anemia, disseminated intravascular coagulation, and transfusion of more than six packed red blood cells.

\section{Statistical Analysis}

Statistical analysis was performed using IBM SPSS software (version 25.0, IBM SPSS Inc., Chicago, IL, USA). All $p$-values were two-tailed, and a probability value of $p<0.05$ was considered statistically significant.

\section{RESULTS}

From January 2009 to December 2018, a total of 8463 patients underwent CRS and HIPEC in German hospitals. In 2017, the largest number of patients was treated $(n=1159)$. There was a predominance of female sex $(1.5: 1$ or 5132:3331 patients).

Colonic origin (C18 in ICD-10-GM) of PSM was highest throughout all the years, reaching its highest level in $2017(55 \% ; n=563)$ and its lowest level in $2012(40 \%$; $n=349$ ). The proportion of gastric origin (C16 ICD-10GM) remained stable over the years $(12-18 \%)$. The proportion of females with ovarian origin (C56 ICD-10-GM) significantly declined over the years from $25 \%(n=98)$ in 2009-9\% $(n=89)$ in 2018. The fourth greatest cause of PSM was peritoneal mesothelioma (C45 ICD-10-GM) with a stable proportion of $5-7 \%$ of patients per year.

The surgical procedures most frequently performed were omentectomy $(47 \% ; n=3979)$, cholecystectomy $(34 \% ; n=2892)$, and colonic and rectal resections $(43 \%$; $n=3669$ ) (Table 1). Minor hepatic resections (8-13\%) and removal of the pancreatic tail $(2-4 \%)$ were performed more seldomly. In total, $24 \%(n=2050)$ of the 8463 patients returned to the operating room (OR) with the highest rate in 2015 (27\%) and with the lowest rate in 2010 (20\%), without reaching statistical significance when comparing 2018 and the previous years (Table 1).

In $17 \%(n=1433)$ of the patients, a protective or a permanent stoma was created with the highest rate in 2015 (20\%) and the lowest rate in $2010(11 \%)$.

Median length of hospital stay did not differ substantially throughout the years and at 23.9 days it reached its maximum in 2017, and its minimum in 2010 at 22.0 days.

Analysis of the total FTR index showed a noticeable improvement over the years, reaching the lowest values in 2017 (9.8\%) and 2018 (8.8\%) without reaching statistical significance between 2018 and the previous years (Table 2). 
TABLE 1 Patient-and treatment characteristics

\begin{tabular}{|c|c|c|c|c|c|c|c|c|c|c|}
\hline Parameter/year & 2018 & 2017 & 2016 & 2015 & 2014 & 2013 & 2012 & 2011 & 2010 & 2009 \\
\hline Number of patients $(n)$ & 1084 & 1159 & 1015 & 1018 & 885 & 822 & 861 & 699 & 515 & 405 \\
\hline Sex (female) $n(\%)$ & $\begin{array}{l}630 \\
\quad(58)\end{array}$ & $\begin{array}{l}656 \\
\quad(57)\end{array}$ & $\begin{array}{l}596 \\
\quad(59)\end{array}$ & $\begin{array}{l}600 \\
\quad(59)\end{array}$ & $\begin{array}{l}534 \\
\quad(60)\end{array}$ & $\begin{array}{l}511 \\
\quad(62)\end{array}$ & $\begin{array}{l}581 \\
\quad(67)\end{array}$ & $\begin{array}{l}437 \\
\quad(63)\end{array}$ & $\begin{array}{l}335 \\
\quad(65)\end{array}$ & $\begin{array}{l}252 \\
\quad(62)\end{array}$ \\
\hline \multicolumn{11}{|l|}{ Tumor etiology, $n(\%)$} \\
\hline Colonic & $\begin{array}{l}563 \\
\quad(54)\end{array}$ & $\begin{array}{l}665 \\
\quad(55)\end{array}$ & $\begin{array}{l}508 \\
\quad(49)\end{array}$ & $\begin{array}{l}500 \\
\quad(49)\end{array}$ & $\begin{array}{l}429 \\
\quad(48)\end{array}$ & $\begin{array}{l}373 \\
\quad(45)\end{array}$ & $\begin{array}{l}349 \\
\quad(40)\end{array}$ & $\begin{array}{l}264 \\
\quad(38)\end{array}$ & $\begin{array}{l}208 \\
\quad(41)\end{array}$ & $\begin{array}{l}165 \\
\quad(42)\end{array}$ \\
\hline Rectal & $30(3)$ & $60(5)$ & $52(5)$ & $55(5)$ & $45(5)$ & $36(4)$ & $33(4)$ & $27(4)$ & $15(3)$ & $14(3)$ \\
\hline Small bowel & $26(2)$ & $29(3)$ & $21(2)$ & $26(3)$ & $25(3)$ & $16(2)$ & $15(2)$ & $11(2)$ & $10(2)$ & $3(1)$ \\
\hline Gastric & $\begin{array}{l}185 \\
\quad(18)\end{array}$ & $\begin{array}{l}185 \\
\quad(18)\end{array}$ & $\begin{array}{l}169 \\
\quad(16)\end{array}$ & $\begin{array}{l}145 \\
\quad(14)\end{array}$ & $\begin{array}{l}141 \\
\quad(16)\end{array}$ & $\begin{array}{l}126 \\
(15)\end{array}$ & $\begin{array}{l}145 \\
\quad(17)\end{array}$ & $\begin{array}{l}125 \\
(18)\end{array}$ & $86(17)$ & $46(12)$ \\
\hline Ovarian & $89(9)$ & $98(8)$ & $\begin{array}{l}132 \\
\quad(13)\end{array}$ & $\begin{array}{l}140 \\
\quad(14)\end{array}$ & $\begin{array}{l}119 \\
\quad(13)\end{array}$ & $\begin{array}{l}140 \\
\quad(17)\end{array}$ & $\begin{array}{l}183 \\
\quad(21)\end{array}$ & $\begin{array}{l}148 \\
\quad(22)\end{array}$ & $\begin{array}{l}109 \\
\quad(22)\end{array}$ & $98(25)$ \\
\hline Mesothelioma & $55(5)$ & $62(5)$ & $65(6)$ & $73(7)$ & $49(6)$ & $52(6)$ & $60(7)$ & $51(7)$ & $36(7)$ & $25(6)$ \\
\hline CUP & $27(2)$ & $38(3)$ & $35(3)$ & $28(3)$ & $26(3)$ & $24(3)$ & $23(3)$ & $24(3)$ & $18(3)$ & $11(3)$ \\
\hline Pancreatic & $11(1)$ & $23(2)$ & $16(2)$ & $13(1)$ & $6(1)$ & $9(1)$ & $15(2)$ & $4(1)$ & $0(0)$ & $9(2)$ \\
\hline Others & $58(5)$ & $50(4)$ & $46(5)$ & $49(5)$ & $45(5)$ & $47(6)$ & $53(6)$ & $33(5)$ & $21(4)$ & $18(4)$ \\
\hline \multicolumn{11}{|l|}{ Surgical procedures, $n(\%)$} \\
\hline Colon/rectal resection & $\begin{array}{l}508 \\
\quad(47)\end{array}$ & $\begin{array}{l}570 \\
\quad(49)\end{array}$ & $\begin{array}{l}468 \\
\quad(46)\end{array}$ & $\begin{array}{l}494 \\
\quad(49)\end{array}$ & $\begin{array}{l}416 \\
\quad(47)\end{array}$ & $\begin{array}{l}394 \\
\quad(48)\end{array}$ & $\begin{array}{l}298 \\
\quad(34)\end{array}$ & $\begin{array}{l}251 \\
\quad(36)\end{array}$ & $\begin{array}{l}159 \\
\quad(31)\end{array}$ & $\begin{array}{l}111 \\
\quad(27)\end{array}$ \\
\hline Omentectomy & $\begin{array}{l}503 \\
\quad(46)\end{array}$ & $\begin{array}{l}508 \\
\quad(44)\end{array}$ & $\begin{array}{l}485 \\
\quad(48)\end{array}$ & $\begin{array}{l}525 \\
\quad(52)\end{array}$ & $\begin{array}{l}391 \\
\quad(44)\end{array}$ & $\begin{array}{l}323 \\
\quad(39)\end{array}$ & $\begin{array}{l}440 \\
\quad(51)\end{array}$ & $\begin{array}{l}357 \\
\quad(51)\end{array}$ & $\begin{array}{l}266 \\
\quad(52)\end{array}$ & $\begin{array}{l}181 \\
\quad(45)\end{array}$ \\
\hline Cholecystectomy & $\begin{array}{l}376 \\
\quad(35)\end{array}$ & $\begin{array}{l}425 \\
\quad(37)\end{array}$ & $\begin{array}{l}379 \\
\quad(37)\end{array}$ & $\begin{array}{l}376 \\
\quad(37)\end{array}$ & $\begin{array}{l}303 \\
\quad(34)\end{array}$ & $\begin{array}{l}297 \\
\quad(36)\end{array}$ & $\begin{array}{l}252 \\
\quad(29)\end{array}$ & $\begin{array}{l}201 \\
\quad(29)\end{array}$ & $\begin{array}{l}170 \\
\quad(33)\end{array}$ & $\begin{array}{l}113 \\
\quad(28)\end{array}$ \\
\hline Minor LR & $\begin{array}{l}119 \\
\quad(11)\end{array}$ & $\begin{array}{l}140 \\
(12)\end{array}$ & $\begin{array}{l}118 \\
\quad(12)\end{array}$ & $\begin{array}{l}107 \\
\quad(11)\end{array}$ & $89(10)$ & $\begin{array}{l}102 \\
\quad(12)\end{array}$ & $\begin{array}{l}102 \\
\quad(12)\end{array}$ & 89 (13) & $58(11)$ & $33(8)$ \\
\hline PT resection & $22(2)$ & $46(4)$ & $29(3)$ & $24(2)$ & $33(4)$ & $36(4)$ & $30(3)$ & $24(3)$ & $15(3)$ & $9(2)$ \\
\hline Splenectomy & $\begin{array}{l}165 \\
\quad(15)\end{array}$ & $\begin{array}{l}209 \\
\quad(18)\end{array}$ & $\begin{array}{l}173 \\
\quad(17)\end{array}$ & $\begin{array}{l}186 \\
\quad(18)\end{array}$ & $\begin{array}{l}134 \\
\quad(15)\end{array}$ & $\begin{array}{l}155 \\
\quad(19)\end{array}$ & $\begin{array}{l}158 \\
\quad(18)\end{array}$ & $\begin{array}{l}138 \\
\quad(20)\end{array}$ & $\begin{array}{l}110 \\
\quad(21)\end{array}$ & $70(17)$ \\
\hline Stoma & $\begin{array}{l}189 \\
\quad(17)\end{array}$ & $\begin{array}{l}218 \\
\quad(19)\end{array}$ & $\begin{array}{l}172 \\
\quad(17)\end{array}$ & $\begin{array}{l}211 \\
\quad(21)\end{array}$ & $\begin{array}{l}134 \\
\quad(15)\end{array}$ & $\begin{array}{l}147 \\
\quad(18)\end{array}$ & $\begin{array}{l}148 \\
\quad(17)\end{array}$ & $\begin{array}{l}103 \\
\quad(15)\end{array}$ & $58(11)$ & $58(14)$ \\
\hline Tracheostoma & $15(1)$ & $21(2)$ & $21(2)$ & $17(2)$ & $16(2)$ & $19(2)$ & $15(2)$ & $6(1)$ & $5(1)$ & $8(2)$ \\
\hline 2nd look & $36(3)$ & $26(2)$ & $25(2)$ & $32(3)$ & $30(3)$ & $28(3)$ & $22(3)$ & $26(4)$ & $22(4)$ & $15(4)$ \\
\hline Back to OR & $\begin{array}{l}249 \\
\quad(23)\end{array}$ & $\begin{array}{l}288 \\
\quad(25)\end{array}$ & $\begin{array}{l}263 \\
\quad(26)\end{array}$ & $\begin{array}{l}270 \\
\quad(27)\end{array}$ & $\begin{array}{l}213 \\
\quad(24)\end{array}$ & $\begin{array}{l}189 \\
\quad(23)\end{array}$ & $\begin{array}{l}193 \\
\quad(22)\end{array}$ & $\begin{array}{l}175 \\
\quad(25)\end{array}$ & $\begin{array}{l}105 \\
\quad(20)\end{array}$ & $\begin{array}{l}105 \\
\quad(26)\end{array}$ \\
\hline Median LOS (days) & 22.2 & 23.7 & 22.8 & 23.3 & 22.9 & 23.5 & 23 & 22.4 & 22 & 22.1 \\
\hline $\begin{array}{l}\text { In-hospital mortality, } n(\%) \\
\quad\left(p \text { value }^{*}\right)\end{array}$ & $30(2.7)$ & $\begin{array}{l}28(2.4) \\
(\mathbf{0 . 6 )}\end{array}$ & $\begin{array}{l}35(3.5) \\
(\mathbf{0 . 3 6 )}\end{array}$ & $\begin{array}{l}37(3.7) \\
(\mathbf{0 . 2 5})\end{array}$ & $\begin{array}{l}31(3.5) \\
(\mathbf{0 . 3 4})\end{array}$ & $\begin{array}{l}35(4.3) \\
(\mathbf{0 . 0 7 )}\end{array}$ & $\begin{array}{l}36(4.2) \\
(\mathbf{0 . 0 8 )}\end{array}$ & $\begin{array}{l}30(4.3) \\
(\mathbf{0 . 0 8})\end{array}$ & $\begin{array}{l}14(2.7) \\
(\mathbf{0 . 9 5 )}\end{array}$ & $\begin{array}{l}14(3.5) \\
(\mathbf{0 . 4 8 )}\end{array}$ \\
\hline
\end{tabular}

Bold values indicate significant at $p<0.05$

$C U P$ cancer of unknown primary, $L R$ liver resection, $L O S$ length of hospital stay, $O R$ operating room, $P T$ pancreatic tail

Especially the management of patients suffering from sepsis and peritonitis improved over the study period. In the year 2018, the FTR index for sepsis was $14.7 \%$ and statistically significantly improved as compared with previous years [2011: $35.5 \% \quad(p=0.01) ; 2013: 32.0 \%$ $(p=0.02)$ and 2015: $29.3 \%(p=0.03)$ ]. In the year 2018, the FTR index for peritonitis was $11 \%$ and also statistically significantly improved when compared with previous years
[2009: $28.1 \%(p=0.0002) ; 2010: 21.2 \% \quad(p=0.0007)$; 2011: $21.1 \%(p=0.0008)$; 2013: $21.8 \%(p=0.0002)$ and 2014: $15.3 \%(p=0.03)$ ] (Table 2).

Total rate of anastomotic insufficiency (AI) was $17.9 \%$ $(n=1515)$ with a statistically significant upward trend from $2009 \quad(p=0.0009), \quad 2010 \quad(p=0.042), \quad 2011$ $(p<0.00001), 2012(p<0.00001)$, and $2013(p=0.0005)$ to 2017 with the highest AI rate $(21.4 \% ; n=248)$. Nevertheless, the management and consecutive FTR index for 
TABLE 2 Cumulative FTR index from 2009 to 2018 for severe but potentially treatable complications

\begin{tabular}{|c|c|c|c|c|c|c|c|c|c|c|}
\hline $\begin{array}{l}\text { FTR-index in } \%(n)(p- \\
\text { value) }\end{array}$ & 2018 & 2017 & 2016 & 2015 & 2014 & 2013 & 2012 & 2011 & 2010 & 2009 \\
\hline Sepsis & $\begin{array}{l}14.7 \\
\quad(11)\end{array}$ & $\begin{array}{c}21.4 \\
(19) \\
(0.27)\end{array}$ & $\begin{array}{c}24.7 \\
(19) \\
(0.12)\end{array}$ & $\begin{array}{c}29.3 \\
(22) \\
\left(\mathbf{0 . 0 3}^{*}\right)\end{array}$ & $\begin{array}{c}20.3 \\
(13) \\
(0.38)\end{array}$ & $\begin{array}{l}32.0(15) \\
(\mathbf{0 . 0 2} *)\end{array}$ & $\begin{array}{l}18.2(8) \\
(0.61)\end{array}$ & $\begin{array}{l}35.5(11) \\
(\mathbf{0 . 0 1} *)\end{array}$ & $\begin{array}{l}18.8(3) \\
(0.68)\end{array}$ & $\begin{array}{l}21.7(5) \\
(0.42)\end{array}$ \\
\hline MI & $0(0)$ & $0(0)$ & $0(0)$ & $0(0)$ & - & $0(0)$ & - & $0(0)$ & - & - \\
\hline APE & $10.8(4)$ & $\begin{array}{l}10.5(4) \\
(0.96)\end{array}$ & $\begin{array}{l}20.1(5) \\
(0.28)\end{array}$ & $\begin{array}{l}14.0(6) \\
(0.67)\end{array}$ & $\begin{array}{l}20.8(5) \\
(0.28)\end{array}$ & $\begin{array}{l}15.0(3) \\
(0.64)\end{array}$ & $\begin{array}{l}17.7(3) \\
(0.48)\end{array}$ & $0(0)$ & $\begin{array}{l}23.1(3) \\
(0.27)\end{array}$ & $0(0)$ \\
\hline Pneumonia & $21.6(8)$ & $\begin{array}{l}17.1(7) \\
(0.61)\end{array}$ & $\begin{array}{l}30.1(8) \\
(0.41)\end{array}$ & $\begin{array}{l}30.4(7) \\
(0.44)\end{array}$ & $\begin{array}{l}15.0(3) \\
(0.54)\end{array}$ & $\begin{array}{l}36.8(7) \\
(0.22)\end{array}$ & $\begin{array}{l}15.8(6) \\
(0.51)\end{array}$ & $0(0)$ & $0(0)$ & $0(0)$ \\
\hline Peritonitis & $6.6(11)$ & $\begin{array}{l}7.5(14) \\
(0.73)\end{array}$ & $\begin{array}{c}11.0 \\
(15) \\
(0.17)\end{array}$ & $\begin{array}{c}11.6 \\
(18) \\
(0.11)\end{array}$ & $\begin{array}{c}15.3 \\
(13) \\
\left(\mathbf{0 . 0 3}^{*}\right)\end{array}$ & $\begin{array}{l}21.8(22) \\
(\mathbf{0 . 0 0 0 2} *)\end{array}$ & $\begin{array}{c}12.6 \\
(12) \\
(0.09)\end{array}$ & $\begin{array}{l}21.1(16) \\
(\mathbf{0 . 0 0 0 8 * )}\end{array}$ & $\begin{array}{l}21.2(7) \\
(\mathbf{0 . 0 0 0 7 * )}\end{array}$ & $\begin{array}{l}28.1(9) \\
(\mathbf{0 . 0 0 0 2} *)\end{array}$ \\
\hline AI & $6.1(13)$ & $\begin{array}{l}5.2(13) \\
(0.70)\end{array}$ & $\begin{array}{c}11.7 \\
(24) \\
(\mathbf{0 . 0 4 * )}\end{array}$ & $\begin{array}{l}6.1(13) \\
(0.97)\end{array}$ & $\begin{array}{l}4.8(8) \\
(0.59)\end{array}$ & $\begin{array}{l}12.8(16) \\
(\mathbf{0 . 0 3} *)\end{array}$ & $\begin{array}{l}8.6(10) \\
(0.37)\end{array}$ & $\begin{array}{l}13.4(11) \\
(\mathbf{0 . 0 3} *)\end{array}$ & $\begin{array}{l}3.4(3) \\
(0.35)\end{array}$ & $\begin{array}{l}10.7(6) \\
(0.22)\end{array}$ \\
\hline AGB & $11.5(3)$ & $\begin{array}{l}28.6(4) \\
(0.17)\end{array}$ & $0(0)$ & $\begin{array}{l}16.7(3) \\
(0.62)\end{array}$ & $\begin{array}{l}40.0(4) \\
(0.053)\end{array}$ & $0(0)$ & $0(0)$ & $0(0)$ & - & - \\
\hline FTR \% $(n)$ (total) & $8.8(50)$ & $9.8(61)$ & $\begin{array}{l}14.5 \\
(71)\end{array}$ & $\begin{array}{l}13.0 \\
(69)\end{array}$ & $\begin{array}{l}12.4 \\
\quad(46)\end{array}$ & $19.5(63)$ & $\begin{array}{l}12.3 \\
(39)\end{array}$ & $15.8(38)$ & 9.9 (16) & $16.0(20)$ \\
\hline$p$-Value (total) & & 0.27 & 0.84 & 0.59 & 0.46 & 0.34 & 0.44 & 0.52 & 0.16 & 0.58 \\
\hline
\end{tabular}

Bold values indicate significant at $p<0.05$

$A G B$ acute gastrointestinal bleeding, $A I$ anastomotic insufficiency, APE acute pulmonary embolism, FTR failure to rescue, $M I$ myocardial infarction

- no reports

patients with AI improved and were seen to be statistically significant when comparing the year 2018 (FTR index $6.1 \%$ ) with the years 2016 (FTR index $11.7 \%$; $p=0.04$ ), 2013 (FTR index 12.8\%; $p=0.03$ ), and 2011 (FTR index $13.4 \% ; p=0.03$ ) (Table 2).

The FTR index depicting pulmonary complications showed the same trend with the lowest values in 2017 (7.5\%) and in 2018 (7.3\%). In particular, intensive care unit (ICU) management of patients suffering from respiratory insufficiency showed the most statistically significant improvement when comparing 2018 with the previous years (Table 3).

Total FTR index for bleeding complications did not show significant differences between years, but the amount of transfused packed red blood cells impacted the FTR index with the cut-off of 6 (FTR index: $\leq 6: 8 \%$ vs. $\geq 6$ : $15 \%)$ and was statistically significant only in 2013 $(p=0.03)$ as compared with 2018 (Table 4).

Acute postoperative kidney failure (N17 ICD10-GM) occurred in $7 \%(n=628)$ of all patients with a cumulative FTR index of $20 \%(n=127)$. The highest failure rate was noted in $2012(33 \% ; n=10)$ and the lowest in $2018(8 \%$; $n=10)$. Therapeutic management statistically significantly improved as seen from a comparison of 2018 with the previous years (for example, 2012 and 2013; $p<0.0001$ ).

Of the 8463 included patients, 290 died during hospital stay, reflecting an in-hospital mortality rate of $3.4 \%$ with the highest rate in $2011(4.3 \% ; n=30)$ and the lowest in $2017(2.4 \% ; n=28)$ (Table 1$)$. There was a trend towards reduced in-hospital mortality when comparing 2018 with 2013 ( $p=0.07), 2012(p=0.08)$, and $2011(p=0.08)$, but without reaching statistical significance.

\section{DISCUSSION}

Since 2009, a steadily rising number of patients have undergone CRS and HIPEC for PSM of gastrointestinal and gynecological primary tumors in Germany. The most frequently applied criticism is that it is an aggressive surgical procedure associated with high morbidity and mortality rates and can therefore delay start of adjuvant systemic chemotherapy. Apart from this, the performance of CRS and HIPEC was, especially for colorectal cancer, critically scrutinized following the negative PRODIGE-7, PROPHYLOCHIP, and COLOPEC trials. On the other 
TABLE 3 FTR-index for pulmonary complications

\begin{tabular}{|c|c|c|c|c|c|c|c|c|c|c|}
\hline $\begin{array}{l}\text { FTR-index in } \\
\%()(p \text {-value })\end{array}$ & 2018 & 2017 & 2016 & 2015 & 2014 & 2013 & 2012 & 2011 & 2010 & 2009 \\
\hline RI & $15.4(15)$ & $\begin{array}{l}15.5(13) \\
(0.98)\end{array}$ & $\begin{array}{l}11.4(23) \\
\left(\mathbf{0 . 0 1 6}^{*}\right)\end{array}$ & $\begin{array}{l}12.5(24) \\
\left(\mathbf{0 . 0 0 6}^{*}\right)\end{array}$ & $\begin{array}{l}12.8(20) \\
\mathbf{( 0 . 0 0 6 * )}^{*}\end{array}$ & $\begin{array}{l}12.4(17) \\
(\mathbf{0 . 0 1} *)\end{array}$ & $\begin{array}{l}14.0(14) \\
(\mathbf{0 . 0 0 6 * )}\end{array}$ & $\begin{array}{l}16.1(10) \\
(\mathbf{0 . 0 0 3} *)\end{array}$ & $\begin{array}{l}12.5(6) \\
(0.06)\end{array}$ & $\begin{array}{l}18.5(5) \\
\left(\mathbf{0 . 0 0 8}^{*}\right)\end{array}$ \\
\hline APE & $10.8(4)$ & $\begin{array}{l}10.5(4) \\
(0.96)\end{array}$ & $\begin{array}{l}20.1(5) \\
(0.28)\end{array}$ & $\begin{array}{l}14.0(6) \\
(0.67)\end{array}$ & $\begin{array}{l}20.8(5) \\
(0.28)\end{array}$ & $\begin{array}{l}15.0(3) \\
(0.64)\end{array}$ & $\begin{array}{l}17.7(3) \\
(0.48)\end{array}$ & $0(0)$ & $\begin{array}{l}23.1(3) \\
(0.27)\end{array}$ & $0(0)$ \\
\hline Pneumonie & $21.6(8)$ & $\begin{array}{l}17.1(7) \\
(0.61)\end{array}$ & $\begin{array}{l}30.1(8) \\
(0.41)\end{array}$ & $\begin{array}{l}30.4(7) \\
(0.44)\end{array}$ & $\begin{array}{l}15.0(3) \\
(0.54)\end{array}$ & $\begin{array}{l}36.8(7) \\
(0.22)\end{array}$ & $\begin{array}{l}15.8(6) \\
(0.51)\end{array}$ & $0(0)$ & $0(0)$ & $0(0)$ \\
\hline PE & $5.2(15)$ & $\begin{array}{l}6.3(20) \\
(0.54)\end{array}$ & $\begin{array}{l}9.0(23) \\
(0.07)\end{array}$ & $\begin{array}{l}10.4(29) \\
(\mathbf{0 . 0 1 8 * )}\end{array}$ & $\begin{array}{l}8.5(17) \\
(0.14)\end{array}$ & $\begin{array}{l}36.8(17) \\
(0.19)\end{array}$ & $\begin{array}{l}8.9(18) \\
(0.10)\end{array}$ & $\begin{array}{l}10.8(17) \\
(\mathbf{0 . 0 2} *)\end{array}$ & $\begin{array}{l}4.6(4) \\
(0.83)\end{array}$ & $\begin{array}{l}12.6(10) \\
\left(\mathbf{0 . 0 1 8}^{*}\right)\end{array}$ \\
\hline Ventilation $>24 \mathrm{~h}$ & $9.8(20)$ & $\begin{array}{l}9.0(21) \\
(0.80)\end{array}$ & $\begin{array}{l}11.1(24) \\
(0.64)\end{array}$ & $\begin{array}{l}10.1(23) \\
(0.90)\end{array}$ & $\begin{array}{l}10.2(19) \\
(0.89)\end{array}$ & $\begin{array}{l}14.3(25) \\
(0.17)\end{array}$ & $\begin{array}{l}11.7(17) \\
(0.55)\end{array}$ & $\begin{array}{l}18.8(22) \\
(\mathbf{0 . 0 2} *)\end{array}$ & $\begin{array}{l}10.5(9) \\
(0.85)\end{array}$ & $\begin{array}{l}7.1(5) \\
(\mathbf{0 . 0 1} *)\end{array}$ \\
\hline FTR \% $(n)$ (total) & $7.3(62)$ & $7.5(65)$ & $11.5(83)$ & $11.7(89)$ & $10.9(64)$ & $12.4(68)$ & $10.6(58)$ & $13.1(49)$ & $8.9(22)$ & $10.5(20)$ \\
\hline$p$-Value (total) & & 0.88 & $0.004 *$ & $0.002 *$ & $0.018 *$ & $0.001 *$ & 0.44 & 0.13 & 0.34 & 0.13 \\
\hline
\end{tabular}

Bold values indicate significant at $p<0.05$

$A P E$ acute pulmonary embolism, $P E$ pleural effusion, $R I$ respiratory insufficiency

TABLE 4 FTR-index for bleeding complications

\begin{tabular}{|c|c|c|c|c|c|c|c|c|c|}
\hline $\begin{array}{l}\text { FTR-rate in } \%(n) \\
(p \text {-value) }\end{array}$ & 2018 & 2017 & 2016 & 2015 & 2014 & 2013 & 2012 & 2011 & 2010 \\
\hline ABA & $4.8(21)$ & $\begin{array}{l}4.3(21) \\
(0.71)\end{array}$ & $\begin{array}{l}5.8(26) \\
(0.50)\end{array}$ & $\begin{array}{l}6.3(28) \\
(0.34)\end{array}$ & $\begin{array}{l}5.9(23) \\
(0.49)\end{array}$ & $\begin{array}{l}7.3(30) \\
(0.12)\end{array}$ & $\begin{array}{l}6.2(25) \\
(0.37)\end{array}$ & $\begin{array}{l}6.5(24) \\
(0.29)\end{array}$ & $\begin{array}{l}4.4(10) \\
(0.80)\end{array}$ \\
\hline DIC & $0(0)$ & $16.7(5)$ & $0(0)$ & $16.7(4)$ & $16.7(4)$ & $0(0)$ & $0(0)$ & $31.3(5)$ & $0(0)$ \\
\hline$\geq 6 \mathrm{PRBC}$ & $20.0(4)$ & $\begin{array}{l}16.7(4) \\
(0.77)\end{array}$ & $\begin{array}{l}23.1(6) \\
(0.80)\end{array}$ & $\begin{array}{l}18.5(5) \\
(0.89)\end{array}$ & $\begin{array}{l}16.7(3) \\
(0.79)\end{array}$ & $\begin{array}{l}24.0(6) \\
(0.74)\end{array}$ & $\begin{array}{l}8.3(3) \\
(0.20)\end{array}$ & $0(0)$ & $0(0)$ \\
\hline FTR \% (n) (total) & $5.3(25)$ & $5.5(30)$ & $6.4(32)$ & $7.4(37)$ & $6.9(30)$ & $8.0(36)$ & $6.1(28)$ & 7.1 (29) & $4.4(10)$ \\
\hline$p$-Value (total) & & 0.85 & 0.44 & 0.17 & 0.30 & 0.09 & 0.58 & 0.25 & 0.60 \\
\hline
\end{tabular}

Bold values indicate significant at $p<0.05$

$A B A$ acute bleeding anemia, DIC disseminated intravascular coagulation, $P R B C$ packed red blood cell

hand, Van Driel and coworkers demonstrated for ovarian cancer and cisplatin-based HIPEC a longer recurrence-free survival and overall survival than for surgery alone, without leading to a higher rate of side-effects. ${ }^{9}$ Despite the strong rationale and evidence for CRS and HIPEC in ovarian cancer, the numbers of patients are steadily decreasing in Germany, mainly due to the negative German guideline recommendation for administration of HIPEC in $2013 .{ }^{26}$

Apart from the oncological benefit, the true impact of the surgical and chemotherapeutic procedures on nationwide in-hospital morbidity and mortality rates is not known, even though in the past a large number of publications have focused on the occurrence, severity, and predisposing parameters of CRS- and HIPEC-associated morbidity. ${ }^{18-23}$ However, the major problem is comparability of results, because indications, HIPEC protocols, surgical technique, and documentation of adverse events are not uniform in Europe and the USA. To gain an insight into the current medical care situation of PSM patients in Germany, we performed a nationwide analysis of in-hospital mortality and morbidity rates. As a surrogate parameter for perioperative management quality, the FTR index, as described earlier, ${ }^{27}$ was calculated and analyzed.

Complete datasets of 8463 patients were analyzed, and we observed an improvement in the FTR index from 2009 to 2018 with the lowest index (8.8\%) in 2018 , but without reaching statistical significance when comparing it with the previous years. In particular, FTR indices for sepsis, peritonitis, pulmonary complications, and acute postoperative 
kidney failure significantly improved over time. These results suggest that the management of severe but potentially treatable complications has been optimized throughout the years. This phenomenon may be attributed to a stricter patient selection process than in earlier years and a steady improvement in postoperative ICU management with evolving options, especially antibiotic treatment of peritonitis-related septic conditions. A retrospective, observational study over 12 years including 101,064 patients with severe sepsis in Australia and New Zealand showed a reduction in mortality in the "surgical admission" subgroup from $25.2 \%$ in 2000 to $12.7 \%$ in $2012 .{ }^{28}$ The same trend was observed in nonseptic ICU patients, so the authors hypothesized that overall changes in ICU practice rather than the management of sepsis explain most of their findings.

With regard to the centralization of PSM management, the results of a French retrospective cohort, multicentric study show that the PCI and the performing center were statistically significantly linked to increased postoperative morbidity. In that study, centers were classified as experienced ( $>7$ years of practice) or inexperienced $(<7$ years of practice). ${ }^{29}$ The data strongly suggest that administration of CRS and HIPEC should be centralized in high-volume centers to guarantee a good patient selection process, surgical technique, and complication management. Unfortunately, the analyzed dataset did not indicate the years of experience the respective center has with PSM treatment, and thus no further conclusions can be drawn.

The quality of the patient selection algorithm, preoperative patient conditioning, and the surgical technique itself are mainly reflected in the rate of reoperation during hospital stay. Data show that, in total, $24 \%$ of all patients returned to the OR with the highest rate seen in 2015 (27\%) and the lowest rate in 2010 (20\%). These rates are generally in line with those of other authors. ${ }^{30,31}$ On the other hand, in a recently published retrospective cohort study from the USA comparing high-risk surgical oncology procedures with CRS and HIPEC, the authors showed a reoperation rate after CRS and HIPEC of only $6.8 \%$. Patients after esophagectomy had the highest reoperation rate $(14.4 \%){ }^{32}$ Another retrospective analysis from the Netherlands showed a total reoperation rate of $16 \% .^{33}$ Patients who had all three preoperatively identified risk factors [PSS (prior surgical score) $>1$, positive smoking history, and Eastern Cooperative Oncology Group (ECOG) score $>1$ ] had a reoperation rate of $45.5 \%$. Our dataset did not specify the reason for reoperation, so that it is possible that minor surgical procedures contributed to the reoperation rate. In another German retrospective analysis, the main reasons for reoperation were $\mathrm{AI}$, fascial rupture, and pancreatitis. ${ }^{34}$ In our presented data, the total AI rate was $17.9 \%$, namely higher than in recent literature, which suggests AI rates between $8 \%$ and $12 \% .{ }^{35-39}$ These elevated AI rates may also explain the slightly increased reoperation rate. Nevertheless, this is the only study presenting nationwide data without any study-related selection bias. Furthermore, the rate of iterative CRS and HIPEC procedures within the study population is not known. It is presumed that repeated procedures are associated with a major late complication rate that is twice as high. ${ }^{40}$ The AI rate in the study by Bekhor and coworkers was $8 \%$ for primary CRS and HIPEC and $14 \%$ for repeated procedures. $^{40}$

The stoma creation rate was $17 \%$, which is in line with other large retrospective analyses from the USA and Israel. ${ }^{41,42}$ Doud and colleagues showed that, in their cohort, only $26 \%$ of potentially reversible stomata were indeed reversed. ${ }^{41}$ The main reasons were tumor progression or death. Furthermore, stoma reversal was associated with $27.9 \%$ of Clavien-Dindo III/IV morbidity. In another US database analysis, the presence of a stoma was associated with a higher 30-day readmission rate. ${ }^{43}$ These data show that, during CRS and HIPEC, stoma creation should be limited to ultralow rectal resections because it has been shown that addition of HIPEC does not impact AI rates and morbidity is elevated during stoma reversal.

These nationwide data showed a total in-hospital mortality rate of $3.4 \%$, which is in line with the international literature $^{44-46}$ and substantially lower than for surgical procedures for pancreatic $(10.1 \%),{ }^{47}$ esophageal cancer $(9.5 \%),{ }^{47}$ and major liver resection $(16.2 \%)^{48}$ in Germany. An NSQIP Database analysis of 1822 patients after CRS and HIPEC showed an overall 30-day mortality of $1.1 \%$, but since crucial treatment- and patient-specific parameters were not mentioned, data must be interpreted with care. In that study, 30-day mortality rates for Whipple's procedure, right lobe hepatectomy, esophagectomy, and trisegmental hepatectomy were $2.5 \%, 2.9 \%, 3.0 \%$, and $3.9 \%$, respectively. On the other hand, 30-day mortality rates following oncologic colorectal surgery were $5 \%^{49}$ and $5.9 \%^{50}$ in studies from France and the USA, respectively. German data indicated an elevated in-hospital mortality rate of $7.5 \%$ following colorectal cancer surgery. ${ }^{47}$ These national and international data should overturn the presumption that CRS and HIPEC is associated with higher morbidity and mortality rates as compared with other high-risk and even low-risk surgical oncology procedures. This misperception becomes even more evident when it is known that approximately 60,000 patients in the USA are diagnosed with PSM every year, but in 2015 only 1000 CRS and HIPEC procedures were performed. ${ }^{32}$

Limitations of this study are surely its retrospective character and the fact that the occurrence of a single severe complication cannot be inevitably linked to the patient's death, even though it is common practice in literature. ${ }^{27}$ 
Furthermore, important patient- and treatment-specific parameters, such as the HIPEC regime and compound, the peritoneal cancer index (PCI), and the completeness of the cytoreduction (CC) score, are missing. Moreover, the level of experience of all contributing centers is not known. Nevertheless, these nationwide data show that CRS and HIPEC is not associated with an elevated mortality rate by comparison with other high-risk surgical oncology procedures, and improvement of FTR indices (especially for sepsis and peritonitis) was linked to decreased in-hospital mortality. Centralization of PSM treatment in high-volume centers is highly recommended to further improve shortand long-term outcomes. Last but not least, these data may help physicians overcome their reluctance to refer patients, especially those with peritoneal metastases of ovarian cancer, to centers of excellence for evaluation for CRS and HIPEC

\section{ACKNOWLEDGMENTS None}

FUNDING Open Access funding enabled and organized by Projekt DEAL.

\section{DISCLOSURES The authors have no disclosures to make.}

OPEN ACCESS This article is licensed under a Creative Commons Attribution 4.0 International License, which permits use, sharing, adaptation, distribution and reproduction in any medium or format, as long as you give appropriate credit to the original author(s) and the source, provide a link to the Creative Commons licence, and indicate if changes were made. The images or other third party material in this article are included in the article's Creative Commons licence, unless indicated otherwise in a credit line to the material. If material is not included in the article's Creative Commons licence and your intended use is not permitted by statutory regulation or exceeds the permitted use, you will need to obtain permission directly from the copyright holder. To view a copy of this licence, visit http://creativecommons. org/licenses/by/4.0/.

\section{REFERENCES}

1. Helm JH, Miura JT, Glenn JA, et al. Cytoreductive surgery and hyperthermic intraperitoneal chemotherapy for malignant peritoneal mesothelioma: a systematic review and meta-analysis. Ann Surg Oncol 2015;22:1686-93.

2. Alexander HR Jr, Bartlett DL, Pingpank JF, et al. Treatment factors associated with long-term survival after cytoreductive surgery and regional chemotherapy for patients with malignant peritoneal mesothelioma. Surgery 2013;153:779-86.

3. Hall B, Padussis J, Foster JM. Cytoreduction and hyperthermic intraperitoneal chemotherapy in the management of colorectal peritoneal metastasis. Surg Clin N Am 2017;97:671-682.

4. Heller DR, Chiuzan C, Taub RN, et al. Recurrence of optimally treated malignant peritoneal mesothelioma with cytoreduction and heated intraperitoneal chemotherapy. Ann Surg Oncol 2017;24:3818-3824.

5. Kepenekian V, Elias D, Passot G, et al. Diffuse malignant peritoneal mesothelioma: Evaluation of systemic chemotherapy with comprehensive treatment through the RENAPE database: multiinstitutional retrospective study. Eur J Cancer 2016;65:69-79.

6. Le Roy F, Gelli M, Hollebecque A, et al. Conversion to complete cytoreductive surgery and hyperthermic intraperitoneal chemotherapy for malignant peritoneal mesothelioma after bidirectional chemotherapy. Ann Surg Oncol 2017;24:3640-3646.

7. Sugarbaker PH, Chang D. Long-term regional chemotherapy for patients with epithelial malignant peritoneal mesothelioma results in improved survival. Eur J Surg Oncol 2017;43:1228-1235.

8. Yan TD, Deraco M, Baratti D, et al. Cytoreductive surgery and hyperthermic intraperitoneal chemotherapy for malignant peritoneal mesothelioma: multi-institutional experience. $J$ Clin Oncol. 2009;27:6237-42.

9. van Driel WJ, Koole SN, Sikorska K, et al. Hyperthermic intraperitoneal chemotherapy in ovarian cancer. $N$ Engl $\mathrm{J} \mathrm{Med}$ 2018;378:230-240

10. Bakrin N, Bereder JM, Decullier E, et al. Peritoneal carcinomatosis treated with cytoreductive surgery and Hyperthermic Intraperitoneal Chemotherapy (HIPEC) for advanced ovarian carcinoma: a French multicentre retrospective cohort study of 566 patients. Eur J Surg Oncol 2013;39:1435-43.

11. Classe JM, Glehen O, Decullier E, et al. Cytoreductive surgery and hyperthermic intraperitoneal chemotherapy for first relapse of ovarian cancer. Anticancer Res 2015;35:4997-5005.

12. Muñoz-Casares FC, Medina-Fernández FJ, Arjona-Sánchez Á, et al. Peritonectomy procedures and HIPEC in the treatment of peritoneal carcinomatosis from ovarian cancer: Long-term outcomes and perspectives from a high-volume center. Eur J Surg Oncol 2016;42:224-33.

13. Ceresoli M, Verrengia A, Montori G, et al. Effect of cytoreductive surgery and hyperthermic intraperitoneal chemotherapy on relapse pattern in primary epithelial ovarian cancer: a propensity score based case-control study. J Gynecol Oncol 2018;29:e53.

14. Cascales-Campos PA, Gil J, Gil E, et al. Treatment of microscopic disease with hyperthermic intraoperative intraperitoneal chemotherapy after complete cytoreduction improves diseasefree survival in patients with stage IIIC/IV ovarian cancer. Ann Surg Oncol 2014;21:2383-9.

15. Cascales-Campos PA, Gil J, Feliciangeli E, et al. The role of hyperthermic intraperitoneal chemotherapy using paclitaxel in platinum-sensitive recurrent epithelial ovarian cancer patients with microscopic residual disease after cytoreduction. Ann Surg Oncol 2015;22:987-93.

16. Königsrainer I, Horvath P, Struller F, et al. Cytoreductive surgery and hyperthermic intraperitoneal chemotherapy in recurrent epithelial ovarian cancer with peritoneal metastases: a single centre experience. Langenbecks Arch Surg 2014;399:589-94.

17. Benhaim L, Faron M, Gelli M, et al. Survival after complete cytoreductive surgery and HIPEC for extensive pseudomyxoma peritonei. Surg Oncol 2019;29:78-83.

18. Cavaliere F, Valle M, De Simone M, et al. 120 peritoneal carcinomatoses from colorectal cancer treated with peritonectomy and intra-abdominal chemohyperthermia: a S.I.T.I.L.O. multicentric study. In Vivo 2006;20:747-50.

19. Gusani NJ, Cho SW, Colovos C, et al. Aggressive surgical management of peritoneal carcinomatosis with low mortality in a high-volume tertiary cancer center. Ann Surg Oncol 2008;15:754-63.

20. Smeenk RM, Verwaal VJ, Zoetmulder FA. Learning curve of combined modality treatment in peritoneal surface disease. $\mathrm{Br} J$ Surg 2007;94:1408-14.

21. Kusamura S, Younan R, Baratti D, et al. Cytoreductive surgery followed by intraperitoneal hyperthermic perfusion: analysis of morbidity and mortality in 209 peritoneal surface malignancies treated with closed abdomen technique. Cancer 2006;106:1144-53. 
22. Glehen O, Osinsky D, Cotte E, et al. Intraperitoneal chemohyperthermia using a closed abdominal procedure and cytoreductive surgery for the treatment of peritoneal carcinomatosis: morbidity and mortality analysis of 216 consecutive procedures. Ann Surg Oncol 2003;10:863-9.

23. Sugarbaker PH, Alderman R, Edwards G, et al. Prospective morbidity and mortality assessment of cytoreductive surgery plus perioperative intraperitoneal chemotherapy to treat peritoneal dissemination of appendiceal mucinous malignancy. Ann Surg Oncol 2006;13:635-44.

24. Chua TC, Yan TD, Saxena A, Morris DL. Should the treatment of peritoneal carcinomatotis by cytoreductive surgery and hyperthermic intraperitoneal chemotherapy still be regarded as a highly morbid procedure? A systematic review of morbidity and mortality. Ann Surg 2009;249:900-907.

25. Sliber JH, Romano PS, Rosen AK, Wang Y, Even-Shoshan O, Volpp KG. Failure-to-rescue: comparing definitions to measure quality of care. Med Care 2007;45:918-925.

26. https://www.leitlinienprogramm-onkologie.de/fileadmin/user_upl oad/Downloads/Leitlinien/Ovarialkarzinom/Version_4/LL_Ovari alkarzinom_Langversion_4.01.pdf

27. Ghaferi AA, Birkmeyer JD, Dimick JB. Complications, failure to rescue and mortality with major inpatient surgery in medicare patients. Ann Surg 2009;250:1029-34.

28. Kaukonen KM, Bailey M, Suzuki S, Pilcher D, Bellomo R. Mortality related to severe sepsis and septic shock among critically ill patients in Australia and New Zealand, 2000-2012. JAMA 2014;311:1308-16.

29. Elias D, Gilly F, Boutitie F, et al. Peritoneal colorectal carcinomatosis treated with surgery and perioperative intraperitoneal chemotherapy: retrospective analysis of 523 patients from a multicentric French study. J Clin Oncol 2010;28:63-8.

30. Glockzin G, Renner P, Popp FC, et al. Hepatobiliary procedures in patients undergoing cytoreductive surgery and hyperthermic intraperitoneal chemotherapy. Ann Surg Oncol 2011;18:1052-9.

31. Navez J, Remue C, Leonard D, et al. Surgical treatment of colorectal cancer with peritoneal and liver metastases using combined liver and cytoreductive surgery and hyperthermic intraperitoneal chemotherapy: report from a single-centre experience. Ann Surg Oncol 2016;23:666-673.

32. Foster JM, Sleightholm R, Patel A, et al. Morbidity and mortality rates following cytoreductive surgery combined with hyperthermic intraperitoneal chemotherapy compared with other high-risk surgical oncology procedures. JAMA Netw Open 2019;2:e186847

33. Simkens GA, van Oudheusden TR, Luyer MD, et al. Predictors of severe morbidity after cytoreductive surgery and hyperthermic intraperitoneal chemotherapy for patients with colorectal peritoneal carcinomatosis. Ann Surg Oncol 2016;23:833-41.

34. Blaj S, Nedelcut S, Mayr M, et al. Re-operations for early postoperative complications after CRS and HIPEC: indication, timing, procedure, and outcome. Langenbecks Arch Surg 2019;404:541-546

35. Younan R, Kusamura S, Baratti D, et al. Bowel complications in 203 cases of peritoneal surface malignancies treated with peritonectomy and closed-technique intraperitoneal hyperthermic perfusion. Ann Surg Oncol 2005;12:910-8.

36. Elias D, Gilly F, Boutitie F, et al. Peritoneal colorectal carcinomatosis treated with surgery and perioperative intraperitoneal chemotherapy: retrospective analysis of 523 patients from a multicentric French study. J Clin Oncol 2010;28:63-8.
37. Glehen O, Gilly FN, Boutitie F, et al. Toward curative treatment of peritoneal carcinomatosis from nonovarian origin by cytoreductive surgery combined with perioperative intraperitoneal chemotherapy: a multi-institutional study of 1,290 patients. Cancer 2010;116:5608-18.

38. Chouliaras K, Levine EA, Fino N, Shen P, Votanopoulos KI. Prognostic factors and significance of gastrointestinal leak after cytoreductive surgery (CRS) with heated intraperitoneal chemotherapy (HIPEC). Ann Surg Oncol 2017;24:890-897.

39. Wiseman JT, Kimbrough C, Beal EW, et al. Predictors of anastomotic failure after cytoreductive surgery and hyperthermic intraperitoneal chemotherapy: does technique matter? Ann Surg Oncol 2020;27:783-792.

40. Bekhor E, Carr J, Hofstedt M, et al. The safety of iterative cytoreductive surgery and HIPEC for peritoneal carcinomatosis: a high volume center prospectively maintained database analysis. Ann Surg Oncol. 2019 Dec 23.

41. Doud AN, Levine EA, Fino NF, Stewart JH, Shen P, Votanopoulos KI. Stoma creation and reversal after cytoreductive surgery with hyperthermic intraperitoneal chemotherapy. Ann Surg Oncol 2016;23:503-10.

42. Jacoby H, Berger Y, Barda L, et al. Implications of stoma formation as part of cytoreductive surgery and hyperthermic intraperitoneal chemotherapy. World J Surg 2018;42:2036-2042.

43. Lee TC, Wima K, Sussman JJ, et al. Readmissions after cytoreductive surgery and hyperthermic intraperitoneal chemotherapy: a US HIPEC collaborative study. J Gastrointest Surg 2020;24:165-176.

44. Elias D, Goere D, Blot F, et al. Optimization of hyperthermic intraperitoneal chemotherapy with oxaliplatin plus irinotecan at 43 degrees $\mathrm{C}$ after complete cytoreductive surgery: mortality and morbidity in 106 consecutive patients. Ann Surg Oncol 2007;14:1818-24.

45. Ceelen WP, Peeters M, Houtmeyers P, Breusegem C, De Somer F, Pattyn P. Safety and efficacy of hyperthermic intraperitoneal chemoperfusion with high-dose oxaliplatin in patients with peritoneal carcinomatosis. Ann Surg Oncol 2008 Feb;15:535-41.

46. Desantis M, Bernard JL, Casanova V, et al. Morbidity, mortality, and oncological outcomes of 401 consecutive cytoreductive procedures with hyperthermic intraperitoneal chemotherapy (HIPEC). Langenbecks Arch Surg 2015;400:37-48.

47. Baum P, Diers J, Lichthardt S, et al. Mortality and complications following visceral surgery. Dtsch Arztebl Int 2019;116:739-746.

48. Filmann N, Walter D, Schadde E, et al. Mortality after liver surgery in Germany. Br J Surg 2019;106:1523-1529.

49. Panis Y1, Maggiori L, Caranhac G, Bretagnol F, Vicaut E. Mortality after colorectal cancer surgery: a French survey of more than 84,000 patients. Ann Surg 2011;254:738-43.

50. de Vries S, Jeffe DB, Davidson NO, Deshpande AD, Schootman M. Postoperative 30-day mortality in patients undergoing surgery for colorectal cancer: development of a prognostic model using administrative claims data. Cancer Causes Control 2014;25:150312.

Publisher's Note Springer Nature remains neutral with regard to jurisdictional claims in published maps and institutional affiliations. 